\title{
Experimental Study and Numerical Simulation of Semi-circled Arch Specimen with SFRC
}

\author{
Zhou Renzhan \\ School of Civil Engineering and Architecture \\ Anhui University of Science and Technology \\ Department of Architecture Administration of
}

\section{Huainan}

Huainan, Peoples Republic of China e-mail: rzzhou@163.com

\author{
Ma Qinyong \\ School of Civil Engineering and Architecture \\ Anhui University of Science and Technology \\ Huainan, Peoples Republic of China \\ e-mail: qyma@aust.edu.cn \\ Jing Laiwang \\ School of Civil Engineering and Architecture \\ Anhui University of Science and Technology \\ Huainan, Peoples Republic of China \\ e-mail: lwjing229@126.com
}

\begin{abstract}
The intention of this paper is to reveal the mechanical properties of steel fiber reinforced concrete (SFRC) at different volume fractions of steel fiber and demonstrate that it can be applied as support in underground coal-mine tunnels. With the similar simulation tests and FLAC finite-element numerical simulation, semicircular concrete specimens at the steel-fiber volume fractions of $0,0.5 \%$ and $1.0 \%$ were investigated. In the similar simulation test, a few of strain gages were distributed in the semicircular-arch specimens to analyze specimens' breaking process, the trend of crack development and the relation of stress versus strain at the measured points at different volume fractions of steel fiber; With the FLAC finite-element numerical simulation, the maximal principal stress distribution of the concrete specimens at three volume fractions of steel fiber was simulated. The results from the numerical simulation and from the simulation test were consistent. Both shed light on the rules that specimen's load-bearing capacity increases with the increase in steel fiber's volume fraction and that its neutral axis moves up with increase of the load. The result will play an important role in cutting down cost in support work, making support work more effective and efficient and developing a sound theory for support design in the coal mines.
\end{abstract}

Keywords-SFRC; model; mechanical property; numerical simulation; tunnel support

\section{INTRODUCTION}

A problem has been existed in the shotcreting support in the deep underground tunnels and not well-addressed for long, i.e. the shotcrete applied is vulnerable to cracking, breaking, dropping and caving. Problems such as caving, rib spalling and heaving floor have become an important part in researches concerning tunnel stability control ${ }^{[1-3]}$. Once the sprayed shotcrete which is a constituent of the support not only to prevent rock from being weathered but also to bear load becomes cracked and broken, its load-bearing capacity would drop drastically. The results from recent years' researches ${ }^{[4-7]}$ indicated that, the low shearing force and tensile force of the plain concrete were primarily responsible for cracked/broken concrete applied. In the part years, some investigations had made contributions to addressing the problems to some degree, for instance, use the steel fiber reinforced concrete as the shotcrete which is a novel composite material formulated by adding a proper amount of short steel fibers irregularly distributed into the conventional concrete ${ }^{[8-9]}$. It is found from the published literature that were made public, of a lot of tests and studies on SFRC a number of researchers had done, most were focused on mechanical properties ${ }^{[10-17]}$. SFRC has been researched more frequently in terms of mechanical properties than glass fiber reinforced concrete (GFRC). As for SFRC research with respect to tunnel support, most were analyzing qualitatively its mechanical properties and field application, and few researches involved numerical simulation on the relation of steel fiber's volume fraction versus the shotcrete load-bearing capacity, let alone the similar simulation tests. To apply SFRC better in the bolt-net shotcrete support in the coal-mine tunnels, it is necessary to investigate the relation of steel fiber's volume fraction of SFRC versus the load-bearing capacity by test and by numerical simulation respectively because the results may contribute to significant cost reduction in tunnel support while it will be of great social and economic implications to mine coals that tend to be increasingly deeper.

\section{EXPERIMENTAL STUDY AND NUMERICAL ANALYSIS OF} SFRC MECHANICAL PROPERTIES

\section{A. Experimental study}

\section{1) Specimens preparation}

In total, 3 groups of specimens were prepared, 4 in each group, in the ratio of cement: stone : sand : water : 
setting accelerator $=1: 2: 2: 0.43: 0.04$, and controlled tests were done for each group at the different volume fractions of steel fiber of $0 \%, 0.5 \%$ and $1.0 \%$, where the steel fiber was $25 \mathrm{~mm}$ long and $0.5 \mathrm{~mm}$ in equivalent diameter.
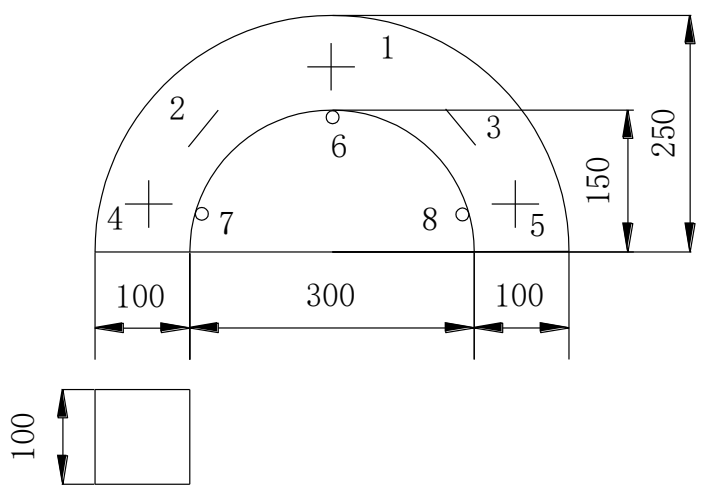

(a)

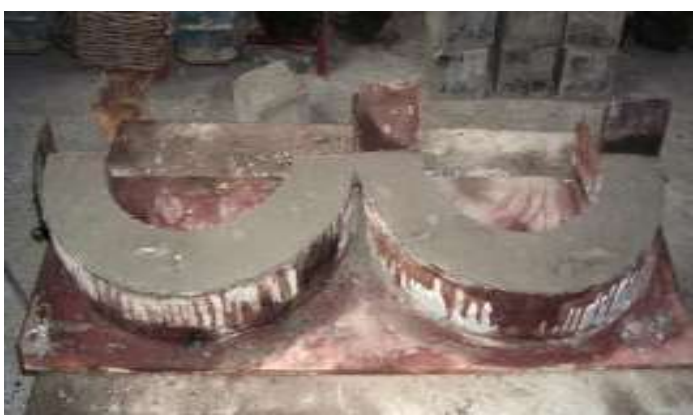

(b)

Figure 1. Arrangement of measuring points and shape of specimens

\section{2) Test program}

To measure accurately the vertical/horizontal deformations of specimens, measuring points were distributed in the front and around its circumference as shown in the Fig.1(a), where two strain gages that cross mutually perpendicularly were arranged on each measuring point except the measuring points 2 and 3 each of which was affixed with a single circumferential strain gauge. To simplify the test, a compressive force was applied to the axial center by a hydraulic pressure tester (Fig .2) and loaded monotonously in stages, about $5 \mathrm{kN}$ each stage. During the subsequent load continuing process, the strain meter was used to measure the axial/horizontal strains of each measuring points until specimens cracked and broke.

Parameters monitored included the cracking load, ultimate load and the deformation.

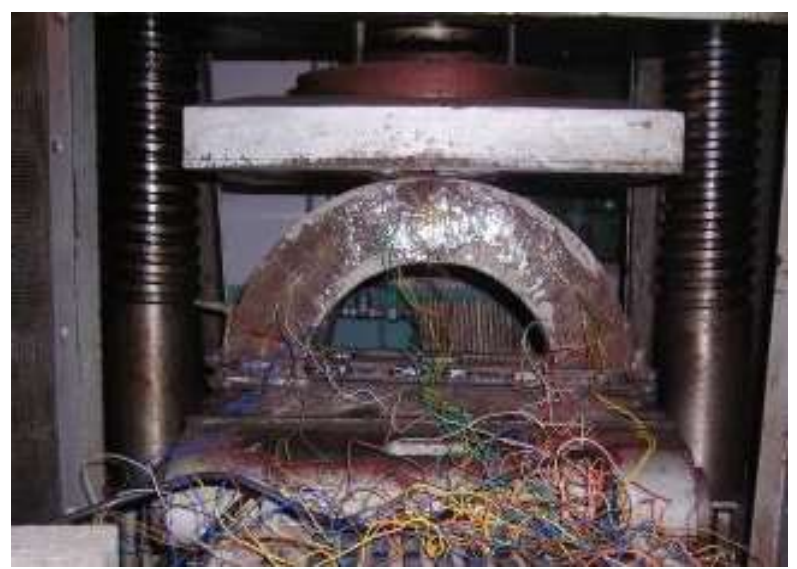

Figure 2. Specimens on loading

\section{3) Test results analysis}

The tested results shown in Fig .3 and 4, specimens underwent three phases described below:

Phase 1: from beginning to generation of the first vertical crack. With increasing pressure, a vertical crack was generated at the top of the arch. It was observed from the test that pressure leading to the first crack was about $40 \% \sim 60 \%$ of the ultimate load-bearing capacity.

Phase 2: with increasing load, the crack extended vertically upwards, wide at the bottom and narrow on the top, while new fine cracks were produced around the outer side of the waist. Cracks were expanding even if the pressure remained the same, and the specimens were close to being broken, in very dangerous condition. The pressure in this phase was $85 \% \sim 90 \%$ of the force at break.

Phase 3: with increasing pressure, the crack got longer and wider rapidly and a vertical through crack came into being while the cracks at the waist were still expanding. Finally, the specimens turned broken due to abrupt widening of the vertical crack.

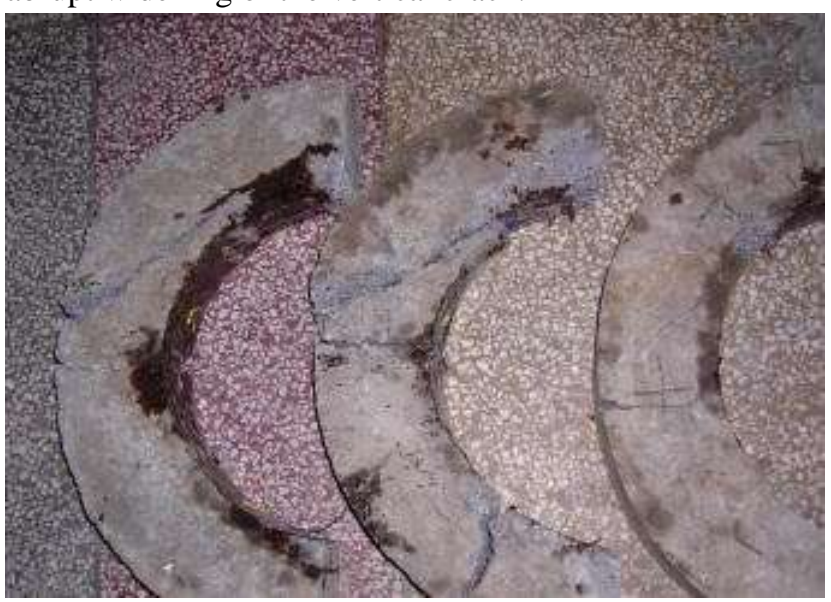

Figure 3. Damaged specimens 

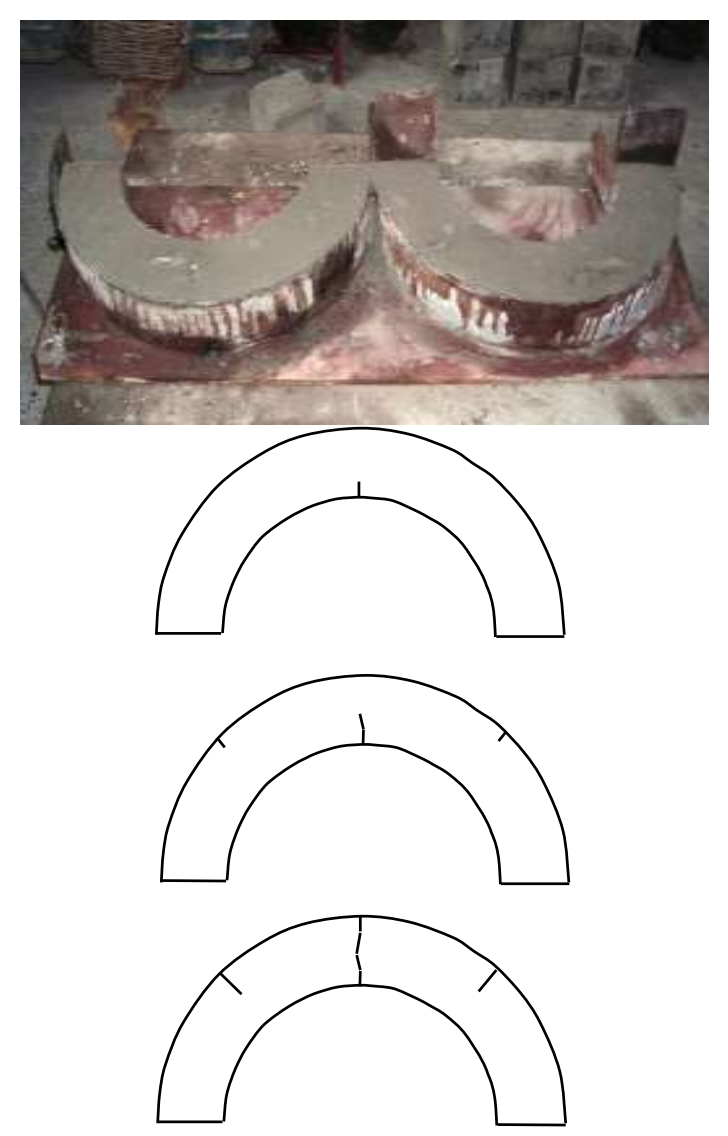

Figure 4. Development of specimens cracking

The positions of strain gages were shown in Fig .1(a) and the corresponding stress versus strain curves were seen in Fig .5(a), (b) and (c).

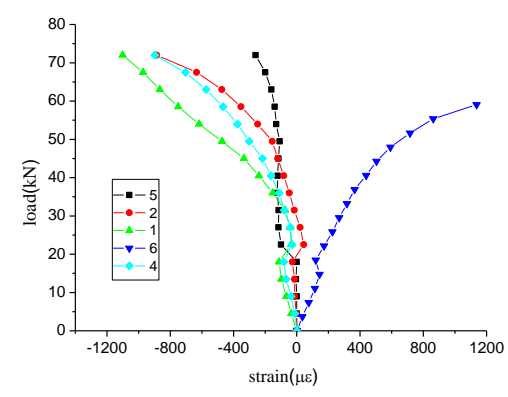

(a) $\rho_{f}=0$

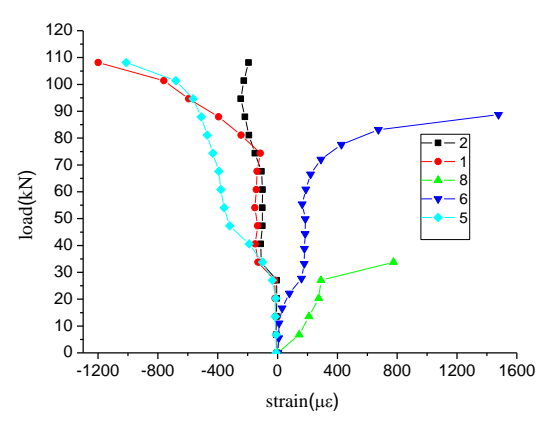

(b) $\rho_{f}=0.5 \%$

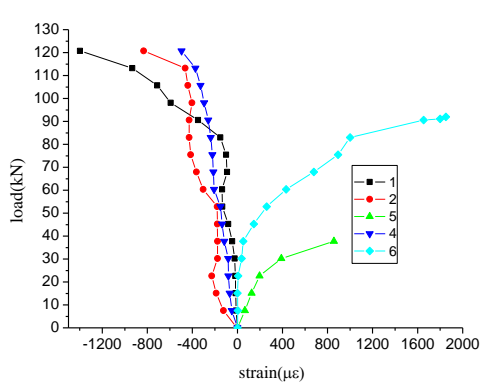

(c) $\rho_{f}=1.0 \%$

Figure 5. Load Vs. strain curves of specimens at three volume fractions of steel fiber at measuring points

TABLE I. NUMERICAL RELATION OF STEEL FIBER VOLUME FRACTION

VERSUS THE ULTIMATE LOAD AND THE MAXIMAL STRAIN

\begin{tabular}{cccc}
\hline $\begin{array}{c}\text { Steel fiber } \\
\text { volume }\end{array}$ & $\begin{array}{c}\text { Ultimate } \\
\text { bearing } \\
\text { fraction }(\%)\end{array}$ & Vertical & Circumferential \\
\hline 0 & 72 & -1101 & 1137 \\
0.5 & 108 & -1199.28 & 1477.5 \\
1.0 & 120 & -1398 & 1850 \\
\hline
\end{tabular}

It is known from the figure and the table shown above, higher volume fraction of steel fiber made for higher ultimate bearing capacity: as compared with normal concrete, the ultimate bearing capacity increases by $50 \%$, the maximal vertical strain by $8 \%$ and the inner circumferential maximal strain by $30 \%$ at the steel-fiber volume fraction of $0.5 \%$; and $67 \%, 27 \%$ and $63 \%$ at $1.0 \%$, respectively; stress concentrates easily at the bottom which is fixed and the process towards breaking contributes to pulling and breaking of concrete in the tensile area at the inner circumferential side. The increasing pull caused the crack to continually expand. In order to reach a new balance, the neutral axis moved upwards, which resulted in increased internal force and reduced cross section. With the neutral axis moving upward, it entered from the tensile stress area to the compressive stress area, and the stress in the compressive stress area was expanding until it reached the ultimate load in which case the specimen broke and the compressive stress at the top reached maximum.

\section{B. Numerical Simulation}

Calculation was done using the finite differential computing program FLAC2D and FLAC3D (Fast Lagrangian Analysis of Continua) developed by an American company - Itasca Consulting Group Inc. The program is primarily applicable to simulate and calculate the mechanical behaviors of geologic materials and geotechnical works, especially fit for the plastic flow developed after a material reaches its yield limit. The material is divided by cells and areas into proper meshes based on the shape of the object to be calculated. Based 
on Lagrange calculation rule that is fit for simulating large deformation and broken materials, FLAC can be used to simulate engineering rock mass that features elasto-plasticity and large nonlinear deformation, reflecting the basic mechanical properties of rock mass, and therefore it allows bringing to light the actual stress state and deformation/damage on specimens $[18,19]$.

Because specimens are geometrically symmetric, a symmetric half was used in calculation. The results from numerical simulation analysis are presented in Fig .6 and Fig .7.

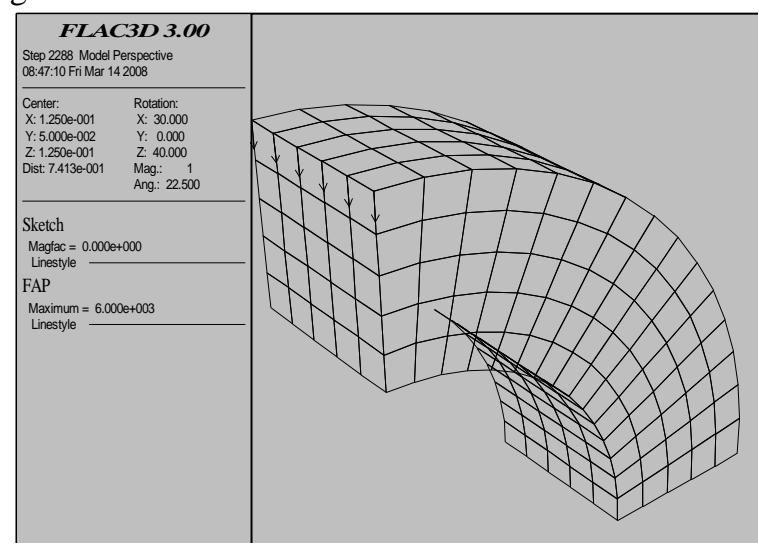

Figure 6. Mesh generation and load application

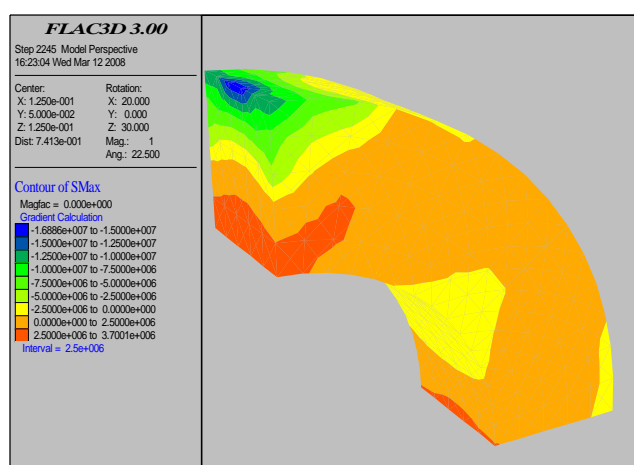

(a) $\rho_{f}=0$

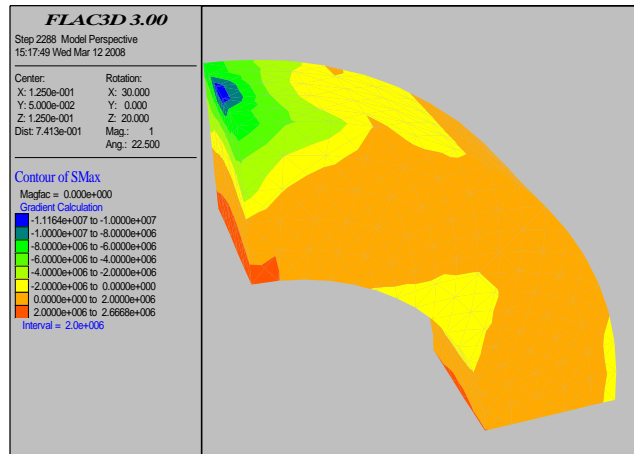

(b) $\rho_{f}=0.5 \%$

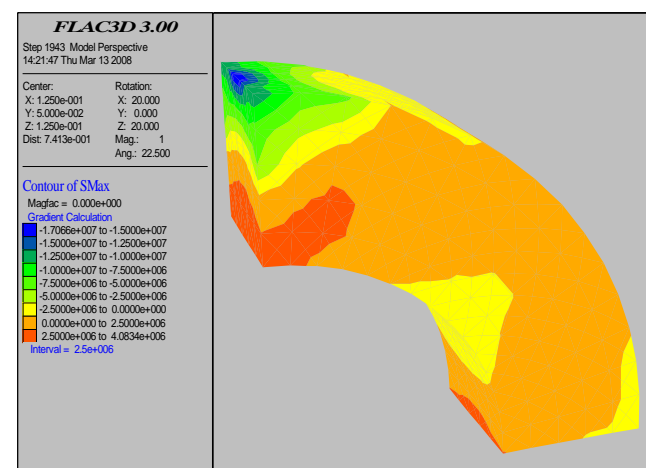

(c) $\rho_{f}=1.0 \%$

Figure 7. Cloud chart of maximal principal stress of concrete specimens at three volume fractions of steel fiber

\section{Comparison and Analysis of Results from Experiment and Numerical Simulation}

Fig .7(a) is the cloud chart of the maximal principal stress at the applied ultimate load of $72 \mathrm{kN}$. It is known from the numerical simulation, the specimen broke starting from the inner circumferential surface at the top of the arch and from the foot, both caused by tensile stress. The tensile stress was 2.0 2.67 MPa, similar to the ultimate tensile strength of normal concrete of $2.75 \mathrm{MPa}$. The tensile strength of concrete at the area under pressure is $10 \mathrm{MPa}$, much lower than the ultimate tensile strength of $21.8 \mathrm{MPa}$. Therefore the damage is mainly caused by broken concrete in the tensile stress area.

Fig .7(b) shows the cloud chart of the maximal principal stress of specimens at the steel-fiber volume fraction of $0.5 \%$ at the applied ultimate load of $108 \mathrm{kN}$. The specimen broke starting from the inner circumferential surface at the top of the arch and from the foot, both caused by tensile stress. The foot was damaged due to concentrated stress. The tensile stress is 2.5 3.7 MPa, and by in-house testing, the ultimate tensile strength of SFRC at the steel fiber volume fraction of $0.5 \%$ is $3.37 \mathrm{MPa}$ which is within the tensile range. In the compressive area, SFRC's compressive strength is $16.9 \mathrm{MPa}$, lower than its ultimate compressive strength of $22.67 \mathrm{MPa}$. Therefore the damage is mainly caused by the broken SFRC in the tensile stress area.

Fig .7(C) shows the cloud chart of the maximal principal stress of specimens at the steel-fiber volume fraction of $1.0 \%$ at the applied ultimate load of $120 \mathrm{kN}$. The specimen broke starting from the inner circumferential surface at the top of the arch and from the foot, both caused by tensile stress. The foot was damaged due to concentrated stress. The tensile stress is 2.5 4.1 MPa and by in-house testing, the ultimate tensile strength of SFRC at the steel fiber volume fraction of $1.0 \%$ is $3.85 \mathrm{MPa}$ which is within the tensile range. In the compressive area, SFRC's compressive strength is 17.1 $\mathrm{MPa}$, lower than its ultimate compressive strength of 23.25 MPa. Therefore the break is mainly caused by the 
broken SFRC in the tensile stress area. This also indicates that continual increase of steel fiber volume fraction beyond the fraction has little impact on its compressive strength.

\section{CONCLUSIONS}

(1) From observing the breaking process of the test on SFRC semi-circular arch specimens at different volume fractions of steel fiber, we know that the break is mainly caused from the tensile force applied to the inner circumferential surface of the arch top of concrete and SFRC, and the results demonstrate that SFRC has good tensile performance and bearing capacity and thus can be applied in support to the underground tunnels of coal mines.

(2) From analyzing the stress versus strain in the test, it is found that, with increasing volume fraction of steel fiber, SFRC's bearing capacity and strain increase, indicating SFRC can be applied to tunnel support where deformation is significant.

(3) By simulating the maximal principal stress distribution of specimens at three volume fractions of steel fiber with FLAC finite-element numerical simulation, the results basically coincidence with the ones from the experiment. Both demonstrates that increase in steel fiber's volume fraction can increase the specimen's bearing capacity and increased load can result in the neutral axial moving upward.

\section{REFERENCES}

[1] NIU Shuang-jian, JING Hong-wen, ZHANG Zhong-yll, et a1. Study on control technology of surrounding rocks in deep soft roadway and its application[J]. Journal of China Coal Society, 2011, 36(6) : 914-919.

[2] BAI Jian-biao, WANG Xiang-yu, JIA Ming-kui, et a1. Theory and application of supporting

in deep soft roadways $[\mathrm{J}]$. Chinese Journal of Geotechnical Engineering,2008, 30(5) : 633-635.

[3] WANG Bo. Study and Application of Bolt-mesh-tight wire Compound Support in the Roadway with Large Deformation[D] . Xi' an University of science and Technology, 2009.
[4] HANNANT D J . Fiber cements and fiber concretes [M]. Translated by LU Jianye. Beijing: China Architecture and Building Press, 1986. (in Chinese)

[5] ZIAD B,JACK Z. Properties of polypropylene fiber reinforced concrete[J]. ACT Material Journal, 1993, 90(6) : 615-618.

[6] KRENCHEL H, SHAH S. Applications of polypropylene fibers to Scandinavia[J]. ACT Concrete International, 1985, 7(3): 32-34.

[7] HE Manchao, ZOU Zhengsheng, ZOU Youfeng. Introduction of soft rock roadway engineering[M] . Xuzhou : China University of Mining and Technology Press,1993. (in Chinese)

[8] WANG Qi-sheng, YAO Hua. Application of reinforced concrete in soft rock tunnel [J]. Journal of Mining \& Safety Engineering, 2008, 25(2): 184-187.

[9] WANG Qi-sheng. Reinforcement mechanism of steel fiber concrete and its applications in support of soft rock roadway[J]. Journal of Liaoning Technical University : Natural science. 2009, 29(3): 337-340.

[10] Shafigh P,Mahmud H,Jumaat M Z. Effect of steel fiber on the mechanical properties of oil palm shell lightweight concrete[J]. Materials and Design, 2011, 32: 3926-3932.

[11] YANG Songlin, DIAO Bo. Mechanical properties of ultra-high performance steel fiber reinforced concrete $[\mathrm{J}]$. Journal of Traffic and Transportation Engineering, 2011, 11(2): 8-13.

[12] Holschemacher K, Mueller T, Ribakov Y. Effect of steel fiber on mechanical properties of high-strength concrete[J]. Materials and Design, 2010, 3: 2604-15.

[13] Olivito R S, Zuccarello F A. An experimental study on the tensile strength of steel fiber reinforced concrete $[\mathrm{J}]$. Composites, 2010, 41: 246-255.

[14] TAGNIT-HAMOU A, VANHOVE Y, PETROV N. Microstructural analysis of the bond mechanism between polyolefin fibers and cement pastes[J]. Cement and Concrete Research, 2005, 35: 364-37.

[15] EDUARDO M A, MANUEL P C. Behavior of normal and steel fiber reinforced concrete under impact of small projectiles[J]. Cement and Concrete Research, 1999, 29: 1807-1814.

[16] LIU Yong-sheng,WANG Xiao-jun,JIN Ting,et a1. Study on the mechanical properties and constitutive relation of steel fiber reinforced concrete[J]. Journal of University of Science and Technology of China, 2007, 37(7): 717-723.

[17] FAN Wen-xi, ZHANG Chang-hai, ZHENG Yong-bao . Endurance research on high-property sprayed concrete[J]. Journal of China Coal Society, 2000, 25(4): 366-368.

[18] Itasca Consulting Group, Inc. Manual of FLAC3D[M].1997.

[19] Manual of UDEC[M].Itasca Consulting Group, Inc. 2005. 